\title{
Care of the Brain-Dead Organ Donor
}

\author{
Julian W. R. Siah' Nazneen Sudhan ${ }^{1}$ Dhuleep S. Wijayatilake' \\ ${ }^{1}$ Neuro Intensive Care, Queen's Hospital, Barking, Havering and \\ Redbridge (BHR), University Hospitals NHS Trust, England

\begin{abstract}
Address for correspondence Dhuleep S. Wijayatilake, BSc (Hons), MBBS, FRCA, FFICM, Neuro Intensive Care, Queen's Hospital, Barking, Havering and Redbridge (BHR) University Hospitals, NHS Trust, England (e-mail: sanjay.wijayatilake@nhs.net).
\end{abstract}

J Neuroanaesthesiol Crit Care 2019;6:167-178

\begin{abstract}
Keywords

- brainstem death physiology

- organ donor care

- organ transplant

There remains a worldwide shortage of organs for transplantation. If not properly cared for, the organs of patients who are brainstem dead will deteriorate, making them either unsuitable for transplantation or reducing the success rate of transplants. The Medline database was searched with no time limit in January 2019 for English publications using keywords "brainstem death physiology" and "organ donor care." Full texts of all publications related to care of deceased donors after brainstem death (DBD) were reviewed. Those that were not relevant were excluded. An online search for publications and guidelines produced by international organizations relating to organ donation and care of the organ donor was also preformed, and the results were reviewed.

Although there is a low level of evidence to support specific management strategies to optimize the care of potential DBD patients, there is reasonable consensus between different international guidelines on protocolized intensive care unit (ICU) management of potential DBD patients and donor resuscitation targets.

Key management concepts include (1) early recognition of brainstem DBD and referral to organ donation services, (2) ICU-led multidisciplinary team (MDT) approach to donor management, (3) shift in ICU teams thinking from management of raised intracranial pressure (ICP) to maintaining organ perfusion and function, (4) early active donor management to normalize donor physiology, and (5) prevention, recognition, and treatment of complications of brainstem death.
\end{abstract}

\section{Introduction}

Since 2008 in the United Kingdom, there has been a reduction in the number of patients dying per year while waiting for an organ transplant. This is due to an increase in donor numbers following several national publicity campaigns. ${ }^{1}$ However, the number of patients on the waiting list still outweighs the number of available donors ( - Fig. 1). Between April 1, 2017 and March 31, 2018, there was a 15\% increase in deceased donors after brainstem death (DBD). ${ }^{1}$ With the continuing high demand for organs, there is a growing pressure on intensive care unit (ICU) services to provide care for potential DBD patients.

DBD, unlike deceased donors after circulatory death (DCD), donate more organs on average per donor (3.7 vs. 2.8 organs), act as the main source of thoracic organs, and provide the opportunity for the condition of the organs to be optimized prior to retrieval and transplantation. ${ }^{1}$

received

February 5, 2019

accepted after revision

May 3, 2019
In 2008, the Organ Donation Taskforce and Academy of Medical Royal Colleges, both produced guidelines outlining the criteria for diagnosing and confirming death by neurological criteria, with the view to improve identification of potential donors. In the United Kingdom, brain death is defined as the irreversible cessation of brainstem function with the irreversible loss of the capacity for consciousness and the capacity to breathe. This is confirmed by (1) presence of known etiology of irreversible brain damage, (2) exclusion of reversible causes of coma and apnea, and (3) absence of brainstem reflexes, absence of movement to noxious stimuli, and presence of apnea on examination., ${ }^{2,3}$

The National Institute for Clinical Excellence (NICE) guidelines on organ donation for transplantation 2011 highlighted the importance of early donor identification of potential DBD patients to fulfill donor wishes and increase the number of organ donors. ${ }^{4}$ Also with increasing demand for organs and waiting list deaths still occurring, the eligibility

Copyright $\odot 2019$ Indian Society of Neuroanaesthesiology and Critical Care
License terms

(1) (1) $\odot \circledast$ 


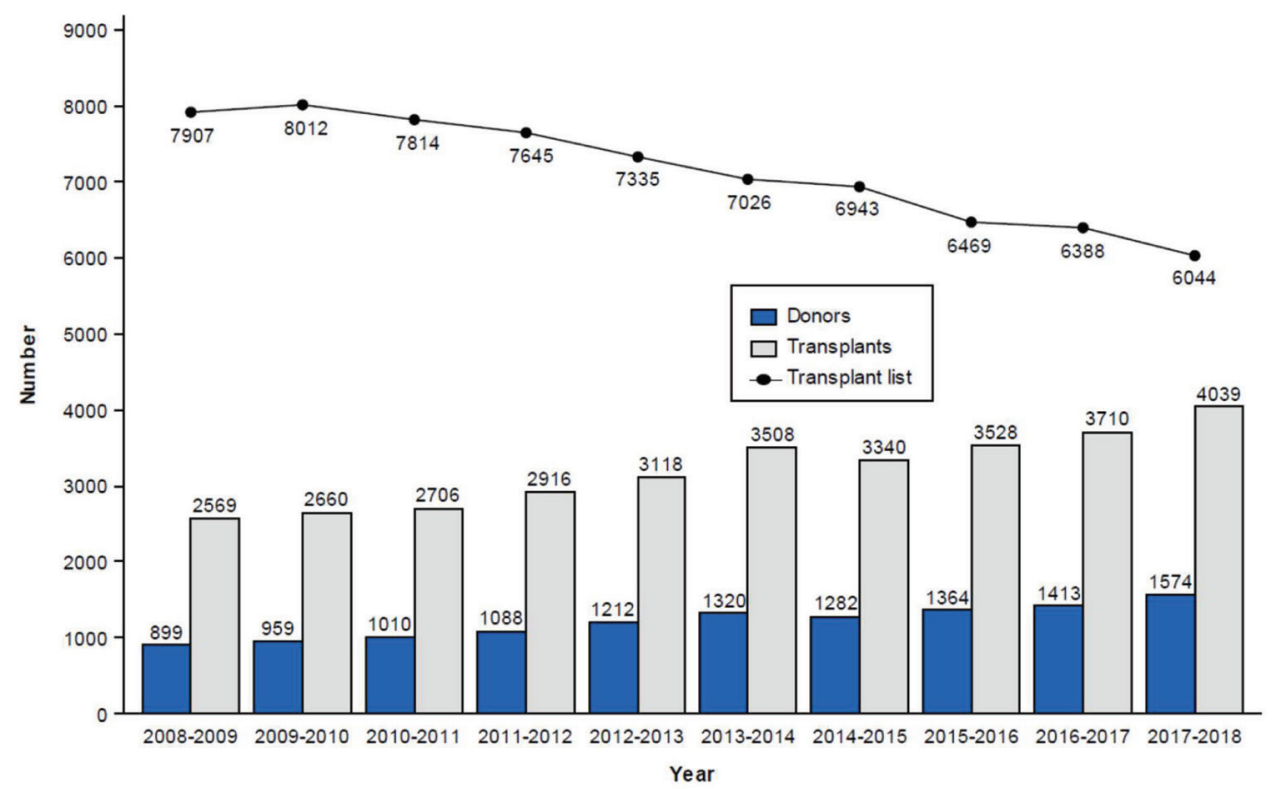

Fig. 1 Comparison of number of deceased donors and transplants in the United Kingdom between April 1, 2008 and March 31, 2018, and number of patients on the active transplant list on March 31 for each year from 2008 to 2018. (Reproduced with permission from Organ Donation and Transplantation Statistical Enquiries, NHS Blood and Transplant, NHS, UK. ${ }^{1}$ )

of donors has been expanded to include extended criteria donors (ECDs). Unlike standard criteria donors (SCDs), ECDs are older and have one or more comorbidities. ${ }^{5}$ Hence, those patients who were previously overlooked are now potential donors and may be more difficult to manage due to their physiological changes associated with advancing age and comorbidities. Furthermore, there are systemic pathophysiological changes that threaten the viability of the organs following brainstem death. ${ }^{6,7}$ Hence, the challenges facing intensivists with the management of potential DBD patients include (1) early identification, (2) management of patients' underlying physiology, acute illness, and comorbidities, and (3) management of the systemic pathophysiological changes that occur following brainstem death.

It has been proposed that the quality of the active management of potential DBD patients, from diagnosis to organ retrieval, is fundamental to the outcome of DBD organs. A prospective multicenter epidemiological study showed that improved hemodynamic status of the donor was associated with less delayed renal graft function in recipients. ${ }^{8}$ Also, early active potential DBD patient management has been shown to be associated with increased organ retrieval in a randomized control trial (RCT). ${ }^{9}$ Another study has shown that the implementation of a structured donor management algorithm improved the number of organs retrieved and transplanted..$^{10}$ However, recent systematic reviews and meta-analyses suggest the level of evidence with regard to the management of potential DBD patients is low according to GRADE criteria and not consistent. ${ }^{11}$

This article reviews the pathophysiological changes associated with brainstem death and the current evidence with regard to the ICU management of potential DBD patients to optimize transplanted organ outcome.

\section{Methods}

The Medline database was searched with no time limit in January 2019 for English publications using keywords: "brainstem death physiology" and "organ donor care." Full texts of all publications related to the care of potential DBD patients were reviewed. Those that were not relevant were excluded. An online search for publications and guidelines produced by international organizations relating to organ donation and care of the organ donor was also preformed, and the results were reviewed.

\section{Pathophysiological Changes Associated with Brainstem Death}

\section{Neurological Changes}

Brainstem death is usually preceded by a variable degree and period of raised intracranial pressure (ICP). As ICP increases and compensatory mechanisms fail, brain-death ensues through two mechanisms: (1) reduced cerebral perfusion pressure (CPP), leading to global hypoxic-ischemic injury and (2) mass effect, leading to cerebellar tonsil foramen magnum herniation and compression of the brainstem, and in turn brainstem ischemia. ${ }^{12}$

Brainstem ischemia progresses in a cephalic to caudal manner. Midbrain ischemia is associated with the loss of consciousness and pupillary light reflexes. Subsequent ischemia of the pons leads to irregular respiration and loss of corneal reflex, cold caloric vestibulo-ocular reflex, and motor response of cranial nerves V and VII. Finally, ischemia of the medulla results in apnea and loss of gag and cough reflexes. With the irreversible loss of the capacity for consciousness and the capacity to breathe, the neurological criteria for brainstem death is fulfilled. ${ }^{2,3,13}$ 


\section{Cardiovascular Changes}

Initially, midbrain ischemia results in parasympathetic nervous system (PNS) stimulation with a resultant period of sinus bradycardia and hypotension. Then pontine ischemia leads to the activation of the sympathetic nervous system (SNS) with an increase in the heart rate, cardiac output (CO), systemic vascular resistance (SVR), and redistribution of blood through peripheral vasoconstriction, resulting in a period of hypertension. Thus, in the face of raised ICP and ischemia, there is an attempt to maintain CPP through increasing the mean arterial pressure (MAP) as CPP $=$ MAP - ICP. ${ }^{13,14}$

This systemic hypertension can be either superimposed onto the bradycardia related to midbrain ischemia or trigger a baroreceptor-mediated reflex bradycardia, which together with irregular respiration seen with brainstem ischemia, is known as Cushing's triad and signifies significant raised ICP. ${ }^{14}$

This period is followed by ischemia of the vagal cardiomotor nucleus in the medulla, which results in an unopposed hyperadrenergic state (catecholamine storm) characterized by intense systemic hypertension. With ischemia of the medulla, this catecholamine storm can coincide with the onset of brainstem death and can occur for a variable period post-brainstem death., ${ }^{2,13}$

Along with systemic hypertension, animal studies have shown significant pulmonary hypertension occurring post-brainstem death due to catecholamine-induced pulmonary vasoconstriction..$^{15}$ This systemic and pulmonary hypertension results in increased afterload on the left and right ventricles, which in turn increases the myocardial work and the oxygen demand, predisposing the 'to ischemia. This is further confounded by catecholamine-induced coronary vasoconstriction and limited increase in coronary blood flow. This results in an imbalance between supply and demand that has been shown in animal studies as the possible mechanism for early cardiac dysfunction post-brainstem death. ${ }^{16}$ This acute myocardial injury seen at the time of brainstem death has been associated with left ventricular systolic dysfunction in approximately $42 \%$ of DBD patients. ${ }^{12}$ The severity of this myocardial injury is linked to the rate of increase in ICP and inotropic dependence. An animal study showed that a rapid increase in ICP compared with a gradual increase was associated with an 800-fold greater increase in adrenaline levels post-brainstem death, and in turn a higher incidence of myocardial ischemia (93\% vs. $23 \%$ ). ${ }^{17}$ A human study utilizing electromicroscopic examination showed up to $25 \%$ of DBD hearts are associated with moderate to severe myocardial injury, with a higher incidence seen in donors initially dependent on high inotropic support. ${ }^{18}$ The catecholamine storm may also precipitate malignant arrhythmias, impairing $\mathrm{CO}$ and end-organ perfusion. ${ }^{19}$ Furthermore, the catecholamine-induced increase in peripheral vascular resistance can impair end-organ perfusion. ${ }^{20}$

The catecholamine storm comes to an end with either depletion of catecholamine stores or through spinal cord ischemia and loss of SNS outflow. This results in vasodilation, reduced preload, and impaired CO. The resulting reduced afterload leads to reduced aortic diastolic pressure and in turn decreased myocardial perfusion. ${ }^{13}$ The resulting hypotension is seen in $81 \%$ of brainstem-dead patients and, if untreated, can result in hypoperfusion and end-organ ischemia. ${ }^{19}$ Furthermore, end organs are susceptible to reperfusion injury when hemodynamic stability is restored, leading to a generalized inflammatory response. ${ }^{13}$

Thus, if unsupported during and post catecholamine storm, potential DBD patients are at high risk of end-organ damage and cardiac arrest.

\section{Respiratory Changes}

The immobile DBD patient with no cough reflex is at high risk of basal atelectasis and pneumonia, leading to ventilation/perfusion ( $\mathrm{V} / \mathrm{Q})$ mismatching and increased fraction of inspired oxygen $\left(\mathrm{FiO}_{2}\right)$ requirements. ${ }^{13}$ Neurogenic pulmonary edema can develop secondary to (1) raised pulmonary capillary hydrostatic pressure due to pulmonary vasoconstriction and increased systemic afterload and (2) increased capillary permeability due to endothelial damage from excess endogenous noradrenaline (NA) release during the catecholamine storm and proinflammatory mediators released from ischemic or necrotic brain tissue. ${ }^{21}$ Hence, the pulmonary vasculature tolerates volume overload poorly, as can occur with cardiovascular (CV) fluid resuscitation. The loss of central respiratory centers would lead to ventilatory failure with irregular respiration and apnea if the patient was not mechanically ventilated. ${ }^{22}$ Ultimately, if these issues are not managed appropriately, they would lead to hypoxic cardiac arrest.

\section{Endocrine Changes}

Post-brainstem death, endocrine dysfunction is multifactorial and varies in severity and timing. Hypothalamus, anterior pituitary, and posterior pituitary function may be lost through ischemia. Also, critical illness stress response, systemic inflammatory response syndrome (SIRS), and highdose steroids may drive endocrine dysfunction. ${ }^{20}$

Animal studies have revealed that after the catecholamine storm, endocrine changes manifest primarily due to anterior and posterior pituitary dysfunction. ${ }^{23}$ Posterior pituitary function is more commonly lost than the anterior. ${ }^{19,24}$ Animal models have shown that antidiuretic hormone (ADH) and adrenocorticotropic hormone (ACTH) levels start to decrease 15 and 45 minutes after brainstem death, respectively. ${ }^{25}$ With a decrease in ADH, neurogenic diabetes insipidus (DI) ensues, with a 65 to $78 \%$ incidence of DI following brainstem death seen in human studies. ${ }^{19,24}$ The associated hypernatremia, hypokalemia, hyperosmolality, and hypovolemia seen with DI may result in end-organ hypoperfusion, and thus compromise donor organ viability. The decrease in ACTH and in turn cortisol levels may impair stress response and in turn further impair hemodynamic stability. However, ACTH changes are less commonly seen, with some studies showing no change in ACTH levels despite reduced cortisol levels. ${ }^{24}$ One study has shown that this may be in part due to a decreased cortisol reserve in DBD patients, with $76 \%$ of DBD patients revealed as nonresponders to ACTH stimulation. ${ }^{26}$ Furthermore, adrenal suppression by high-dose steroids, used for the management of raised ICP prior to 
brainstem death diagnosis, may be the underlying cause for the low cortisol levels. ${ }^{24}$

Several human studies have shown a euthyroid sick syndrome picture post-brainstem death with low levels of free triiodothyronine ( $\mathrm{fT}_{3}$ ) and free tetraiodothyronine $\left(\mathrm{fT}_{4}\right)$, normal or raised reverse $\mathrm{T}_{3}$, and normal thyroid-stimulating hormone levels. ${ }^{23,24,27,28}$ Controversy remains over the importance of thyroid dysfunction and replacement in potential DBD patients. Some studies have shown no link between low thyroid levels and hemodynamic instability or lactate levels in DBD patients. ${ }^{27,28}$ However, others propose a link between reduced $\mathrm{fT}_{3}$ and reduced myocardial energy stores, leading to increased anaerobic metabolism, lactic acidosis, and impaired cardiac contractility. ${ }^{29-31}$

Post-brainstem death insulin level decreases and peripheral insulin resistance increases. This results in intracellular hypoglycemia and a shift toward anaerobic metabolism, and extracellular hyperglycemia and shift toward a hyperosmolar state with osmotic diuresis and hypovolemia. ${ }^{23,32}$ This hyperglycemia may be worsened by the use of high-dose steroids and increased catecholamine levels.

Loss or impaired function of the hypothalamus leads to loss of central thermoregulation. During the catecholamine storm, there may be a period of hyperpyrexia. However, post-catecholamine storm, the patient is more susceptible to rapidly becoming hypothermic due to the loss of SNS outflow and resulting profound peripheral vasodilation. This is further confounded by the lack of skeletal muscle activity and reduced metabolic activity of the potential DBD patient. If untreated, hypothermia results in bradyarrhythmias, reduced CO, hypotension, impaired microcirculation, cold-induced diuresis, and leftward shift of the oxyhemoglobin dissociation curve, thus impairing end-organ perfusion and oxygenation. ${ }^{30}$

\section{Hematological Changes}

Following brainstem death, coagulation may be impaired either through hypothermia, dilution of coagulation factors, or via precipitation of disseminated intravascular coagulation (DIC). In this context, DIC can be induced by plasminogen activator and thromboplastin released from ischemic or necrotic brain tissue in brainstem-dead patients, with an incidence of $28 \%{ }^{19}$ Furthermore, plasminogen activator and excess catecholamines can impair platelet function. ${ }^{33}$

\section{Immunological Changes}

A systemic inflammatory response is seen post-brainstem death due to release of proinflammatory mediators from ischemic or necrotic brain tissue and upregulation of peripheral inflammatory mediators, such as cytokines and adhesion molecules. ${ }^{23}$ Furthermore, if brainstem deathassociated $\mathrm{CV}$ changes are poorly managed, inflammatory mediators may be released from ischemic tissue and in response to subsequent ischemic-reperfusion injury. ${ }^{22}$ These inflammatory mediators can worsen hemodynamic stability and neurogenic pulmonary edema. Furthermore, the presence of high levels of cytokines and adhesion molecules in donor organs have been associated with accelerated acute graft rejection. ${ }^{34}$

\section{Systematic Treatment Approach}

The general aims of active potential DBD patient management protocols are to resuscitate the donor and maintain organ perfusion and function, maximizing the number and quality of transplantable organs, and thus improving recipient outcome. There is a reasonable consensus among international guidelines with regard to donor resuscitation targets ( $\mathbf{- T a b l e ~} \mathbf{1}$ ) and management strategies ( - Table 2). ${ }^{35-41}$

\section{Cardiovascular Support}

Following brainstem death, the aim is to reduce the $\mathrm{CV}$ response to the catecholamine storm and support the $\mathrm{CV}$ system post-catecholamine storm, hence maintaining cardiac and end-organ perfusion.

\section{Cardiovascular Monitoring}

Potential DBD patients are susceptible to desaturation, arrhythmia, myocardial ischemia, and hemodynamic instability. Hence, international guidelines promote the use of multiple measured variables to determine therapy. Along with standard ICU monitoring, CO monitoring may be required. ${ }^{13}$ $\mathrm{CO}$ monitoring is indicated if left ventricular ejection fraction (LVEF) is $\leq 40 \%$ or if there is an escalation in inotropic or vasopressor support. The insertion of a pulmonary artery catheter (PAC) allows monitoring of mixed venous oxygen saturation and hemodynamic parameters. In addition, PAC is required for evaluation of the heart and lungs for donation. ${ }^{35}$ This has been advocated by the Papworth hospital transplant program study that showed that utilization of PAC to guide CV resuscitation improved the function of $92 \%$ of organs that were initially considered unsuitable for transplantation. ${ }^{42}$ Although the less invasive esophageal Doppler may be more desirable if the heart and lungs are not being considered for donation. Other minimally invasive hemodynamic monitors utilizing the pulse contour analysis technique, such as LiDCO Plus, have not been shown to be beneficial in the management of potential DBD patients in the recent Monitoring Organ donors to Improve Transplantation Results (MOnIToR) trial. ${ }^{43}$

\section{Cardiovascular Investigations}

Potential DBD patients considered for cardiac donation should have a base line 12-lead electrocardiogram (ECG) for arrhythmias and ischemia and a transthoracic echocardiogram (TTE) to identify any structural abnormalities that may preclude heart transplantation. However, it has been shown that $50 \%$ of functionally abnormal hearts on initial TTE can improve to meet hemodynamic transplant criteria following active DBD patient management. ${ }^{44}$ Hence, a single TTE assessment should not be used to rule out donor suitability and repeat TTE should be considered if initial impaired function is shown.

A small study has suggested high donor levels of troponin correlates with high incidence of cardiac rejection. ${ }^{45}$ However, the American consensus guidelines for management of cardiac donors concluded that high troponin levels can be present in donors without ventricular dysfunction and there is poor quality of evidence linking troponin levels 
Table 1 International donor resuscitation targets

\begin{tabular}{|c|c|c|c|c|c|}
\hline Guidelines & UNOS $(1999)^{38}$ & American $(2001)^{36,37}$ & Canadian $(2006)^{35}$ & UK $(2012)^{39,40}$ & Eurotransplant $(2015)^{41}$ \\
\hline \multicolumn{6}{|l|}{ Respiratory } \\
\hline Saturations & $\geq 95 \%$ & $\geq 95 \%$ & $\geq 95 \%$ & $\geq 95 \%$ & $\geq 95 \%$ \\
\hline $\mathrm{PaO}_{2}$ & $\geq 12 \mathrm{kPa}$ & $\geq 10.7 \mathrm{kPa}$ & $\geq 10.7 \mathrm{kPa}$ & $\geq 10 \mathrm{kPa}$ & $>13.3 \mathrm{kPa}$ \\
\hline $\mathrm{PaCO}_{2}$ & $4-4.7 \mathrm{kPa}$ & $4-4.7 \mathrm{kPa}$ & $4.7-6.0 \mathrm{kPa}$ & $5-6.5 \mathrm{kPa}^{\mathrm{a}}$ & $4.6-6.0 \mathrm{kPa}$ \\
\hline Tidal volume & $10-15 \mathrm{~mL} / \mathrm{kg}$ & $8-10 \mathrm{~mL} / \mathrm{kg}$ & $8-10 \mathrm{~mL} / \mathrm{kg}$ & $4-8 \mathrm{~mL} / \mathrm{kg}$ & $6-8 \mathrm{~mL} / \mathrm{kg}$ \\
\hline PEEP & $5 \mathrm{~cm} \mathrm{H}_{2} \mathrm{O}$ & $5 \mathrm{~cm} \mathrm{H}_{2} \mathrm{O}$ & $5 \mathrm{~cm} \mathrm{H}_{2} \mathrm{O}$ & $5-10 \mathrm{~cm} \mathrm{H}_{2} \mathrm{O}$ & $5-10 \mathrm{~cm} \mathrm{H}_{2} \mathrm{O}$ \\
\hline PIP & $\leq 30 \mathrm{~cm} \mathrm{H}_{2} \mathrm{O}$ & $\leq 30 \mathrm{~cm} \mathrm{H}_{2} \mathrm{O}$ & $\leq 30 \mathrm{~cm} \mathrm{H}_{2} \mathrm{O}$ & $\leq 30 \mathrm{~cm} \mathrm{H}_{2} \mathrm{O}$ & $\leq 35 \mathrm{~cm} \mathrm{H}_{2} \mathrm{O}$ \\
\hline \multicolumn{6}{|l|}{ Cardiovascular } \\
\hline Heart rate & $\begin{array}{l}70-120 \text { beats/ } \\
\text { min }\end{array}$ & - & $60-120$ beats/min & $\begin{array}{l}60-100 \text { beats/ } \\
\min \end{array}$ & - \\
\hline SBP & $>90 \mathrm{~mm} \mathrm{Hg}$ & - & $>100 \mathrm{~mm} \mathrm{Hg}$ & $>100 \mathrm{~mm} \mathrm{Hg}$ & $\geq 90 \mathrm{~mm} \mathrm{Hg}$ \\
\hline MAP & $\geq 60 \mathrm{~mm} \mathrm{Hg}$ & $\geq 60 \mathrm{~mm} \mathrm{Hg}$ & $\geq 70 \mathrm{~mm} \mathrm{Hg}$ & $60-80 \mathrm{~mm} \mathrm{Hg}$ & $70-90 \mathrm{~mm} \mathrm{Hg}$ \\
\hline CVP & $\leq 12 \mathrm{~mm} \mathrm{Hg}$ & 6-10 mm Hg & $6-10 \mathrm{~mm} \mathrm{Hg}$ & 4-10 mm Hg & 6-10 mm Hg \\
\hline Urine output & $1-3 \mathrm{~mL} / \mathrm{kg} / \mathrm{h}$ & $\geq 1 \mathrm{~mL} / \mathrm{kg} / \mathrm{h}$ & $0.5-3 \mathrm{~mL} / \mathrm{kg} / \mathrm{h}$ & $0.5-2 \mathrm{~mL} / \mathrm{kg} / \mathrm{h}$ & $1-2 \mathrm{~mL} / \mathrm{kg} / \mathrm{h}$ \\
\hline PCWP & $\leq 12 \mathrm{~mm} \mathrm{Hg}$ & $8-12 \mathrm{~mm} \mathrm{Hg}$ & $6-10 \mathrm{~mm} \mathrm{Hg}$ & $<12 \mathrm{~mm} \mathrm{Hg}$ & $10-15 \mathrm{~mm} \mathrm{Hg}$ \\
\hline Cardiac index & $>2.5 \mathrm{~L} / \mathrm{min} / \mathrm{m}^{2}$ & $>2.4 \mathrm{~L} / \mathrm{min} / \mathrm{m}^{2}$ & $>2.4 \mathrm{~L} / \mathrm{min} / \mathrm{m}^{2}$ & $>2.1 \mathrm{~L} / \mathrm{min} / \mathrm{m}^{2}$ & - \\
\hline SVR or SVRI & $\begin{array}{l}\text { SVR } 800-1,200 \\
\text { dyne.s/cm }\end{array}$ & $\begin{array}{l}\text { SVR } 800-1,200 \\
\text { dyne.s/cm }\end{array}$ & $\begin{array}{l}\text { SVR } 800-1,200 \\
\text { dyne.s/cm }\end{array}$ & $\begin{array}{l}\text { SVRI } 1,800- \\
2,400 \text { dyne.s/ } \\
\mathrm{cm}^{5} / \mathrm{m}^{2}\end{array}$ & - \\
\hline $\mathrm{ScvO}_{2}$ & - & - & $\geq 60 \%$ & $>60 \%$ & - \\
\hline \multicolumn{6}{|c|}{ Metabolic and Endocrine } \\
\hline $\mathrm{pH}$ & $7.40-7.45$ & $7.40-7.45$ & $7.35-7.45$ & $7.25-7.45$ & - \\
\hline Blood glucose & $6.7-10 \mathrm{mmol} / \mathrm{L}$ & $4.4-10 \mathrm{mmol} / \mathrm{L}$ & $4-8 \mathrm{mmol} / \mathrm{L}$ & 4-10 mmol/L & $6.6-9.9 \mathrm{mmol} / \mathrm{L}$ \\
\hline Temperature & $36.5-37.5^{\circ} \mathrm{C}$ & $>35^{\circ} \mathrm{C}$ & $>35^{\circ} \mathrm{C}$ & $36-37.5^{\circ} \mathrm{C}$ & $35-37^{\circ} \mathrm{C}$ \\
\hline Sodium & $<150 \mathrm{mmol} / \mathrm{L}$ & $<150 \mathrm{mmol} / \mathrm{L}$ & $130-150 \mathrm{mmol} / \mathrm{L}$ & $<150 \mathrm{mmol} / \mathrm{L}$ & $134-150 \mathrm{mmol} / \mathrm{L}$ \\
\hline \multicolumn{6}{|l|}{ Hematological } \\
\hline $\mathrm{Hb}$ & $\geq 10 \mathrm{~g} / \mathrm{L}$ & $\geq 10 \mathrm{~g} / \mathrm{L}$ & $\geq 70 \mathrm{~g} / \mathrm{L}$ & $\geq 70 \mathrm{~g} / \mathrm{L}$ & $>96 \mathrm{~g} / \mathrm{L}$ \\
\hline $\mathrm{HCT}$ & $\geq 30 \%$ & $\geq 30 \%$ & - & - & $>20 \%$ \\
\hline
\end{tabular}

Abbreviations: CVP, central venous pressure; $\mathrm{Hb}$, hemoglobin levels; $\mathrm{HCT}$, hematocrit; MAP, mean arterial pressure; PaCO ${ }_{2}$, partial pressure of carbon dioxide; $\mathrm{PaO}_{2}$, partial pressure of oxygen; PEEP, positive end-expiratory pressure; PCWP, pulmonary capillary wedge pressure; PIP, peak inspiratory pressure; $\mathrm{ScVO}_{2}$, central or mixed venous saturation; SBP, systolic blood pressure; SVR or SVRI, systemic vascular resistance or systemic vascular resistance index; UNOS, united network for organ sharing. ${ }^{a}$ or higher as long as $\mathrm{pH}>7.25$.

with acute graft failure. ${ }^{36}$ Canadian guidelines recommend serial troponin levels every 12 hours and recommend that one considers performing a coronary angiogram when the following donor factors are present: older heart donors, CV risk factors, history of coronary heart disease, ischemia on ECG, regional wall motion abnormalities, or $\mathrm{LVEF} \leq 40 \%{ }^{35}$

\section{Management of Catecholamine Storm}

The occurrence of the catecholamine storm in a brainstemdead patient has been defined as the acute and sustained (> 10 minutes) increase in systolic blood pressure (SBP) $>200$ $\mathrm{mm} \mathrm{Hg}$ with a heart rate $(\mathrm{HR})>140$ beats/min in the absence of any other cause. ${ }^{46} \mathrm{~A}$ retrospective study showed this occurs in approximate $63 \%$ of brainstem-dead patients. This study also showed that active treatment of the catecholamine storm using short-acting antihypertensives improved LVEF and the success rate of cardiac transplantation. ${ }^{46}$ Unfortunately, the power of the study did not allow comparison between different antihypertensives to determine the most effective agent. Despite this, international guidelines recommend esmolol or sodium nitroprusside infusions as first-line agents to be started if MAP remains $>90 \mathrm{~mm} \mathrm{Hg}$ or SBP remains $\geq 160 / 90 \mathrm{~mm} \mathrm{Hg.}{ }^{35,47}$

\section{Management Post-Catecholamine Storm Fluid Management}

Post-catecholamine storm-associated vasoplegia and hypotension need to be supported with adequate fluid resuscitation and vasopressor and/or inotropic support. Maintaining euvolemia is supported by a prospective observational study of DBD patients, which showed preload responsiveness (a pulse pressure variation $[\mathrm{PPV}]>13 \%$ ) was associated with higher cytokine levels and lower number of viable organs for transplantation. ${ }^{48}$ Most advocate the use of balanced crystalloid solutions over colloids for fluid resuscitation in potential DBD patients, 
Table 2 Summary of donor management as per current literature $22,35,36,40,41$

\begin{tabular}{|c|c|}
\hline Support & \\
\hline Respiratory & $\begin{array}{l}\text { Lung-protective ventilation: Tidal volume } 4-8 \mathrm{~mL} / \mathrm{kg} \text { of IBW, PEEP } 5-10 \mathrm{~cm} \mathrm{H} \mathrm{O} \text {, PIP } \leq 30 \mathrm{~cm} \mathrm{H}_{2} \mathrm{O} \text {, } \\
\text { lowest possible } \mathrm{FiO}_{2} \text { to achieve } \mathrm{PaO}_{2} \geq 10 \mathrm{kPa} \text { (ideally }<0.4 \text { ), and relative normocapnia with } \mathrm{pH}>7.25 \text {. } \\
\text { Conservative fluid management approach: If } \mathrm{PaO}_{2} / \mathrm{Fi} \mathrm{O}_{2} \text { ratio }<300 \text {, consider diurese to normovolemia }\end{array}$ \\
\hline Cardiovascular & $\begin{array}{l}\text { Management of catechomlamine storm: If SBP } \geq 160 / 90 \mathrm{~mm} \mathrm{Hg} \text { or MAP }>95 \mathrm{~mm} \mathrm{Hg} \text { wean inotro- } \\
\text { pic/vasopressor support and consider short-acting antihypertensives: } \\
\text { Esmolol: } 100-500 \mu \mathrm{g} / \mathrm{kg} \text { IV bolus followed by } 100-300 \mu \mathrm{g} / \mathrm{kg} / \mathrm{min} \text { IVI } \\
\text { Na nitroprusside: } 0.5-5 \mu \mathrm{g} / \mathrm{kg} / \mathrm{min} \mathrm{IVI} \\
\text { Management post catecholamine storm: Use multiple measured variables, including cardiac output } \\
\text { (if available), to guide resuscitation to achieve CV targets } \\
\text { Fluid resuscitate with crystalloids to euvolemia } \\
\text { Inotropes/vasopressors: } \\
\text { First line: vasopressin } 0-4 \mathrm{U} / \mathrm{h} \text { IVI and avoid catecholamines if possible } \\
\text { If needed, avoid high-dose catecholamines (NA }<0.2 \mu \mathrm{g} / \mathrm{kg} / \mathrm{min} \text { or dopamine } \leq 10 \mu \mathrm{g} / \mathrm{kg} / \mathrm{min} \text { ) } \\
\text { Consider } \mathrm{T}_{3} \text { IV bolus and IVI if CV unstable despite conventional therapy }\end{array}$ \\
\hline Renal & $\begin{array}{l}\text { Avoid positive fluid balance and aim for } 0.5-3 \mathrm{~mL} / \mathrm{kg} / \mathrm{h} \\
\text { Avoid nephrotoxic drugs and minimize exposure to IV contrast } \\
\text { Correct electrolyte abnormalities }\end{array}$ \\
\hline Hepatic & Maintain liver glycogen stores with enteral feeding or glucose infusion. Avoid hepatoxic drugs \\
\hline Endocrine & $\begin{array}{l}\text { Consider combined } \mathrm{HT} \text { if } \mathrm{LVEF} \leq 40 \% \text { or hemodynamic instability remains despite conventional } \\
\text { therapy: } \\
\text { - } \mathrm{T}_{3}: 4 \mu \mathrm{g} \text { IV bolus followed by } 3 \mu \mathrm{g} / \mathrm{h} \text { IVI or } \mathrm{T}_{4}: 20 \mu \mathrm{g} \text { IV bolus followed by } 10 \mu \mathrm{g} / \mathrm{h} \text { IVI } \\
\text { - Vasopressin: } 1 \mathrm{U} \text { IV bolus followed by } 0-4 \mathrm{U} / \mathrm{h} \mathrm{IVI} \\
\text { - Methylprednisolone } 15 \mathrm{mg} / \mathrm{kg} \text { (max. } 1 \mathrm{~g} \text { ) IV every } 24 \mathrm{~h} \\
\text { Identify and correct DI: Consider DI if: UO }>4 \mathrm{~mL} / \mathrm{kg} / \mathrm{h} \text { with serum Na } \geq 145 \mathrm{mmol} / \mathrm{L} \text {, and/or serum } \\
\text { osmolarity } \geq 300 \mathrm{mOsmol} / \mathrm{kg} \text {, and/or urine osmolarity } \leq 200 \mathrm{mOsmol} / \mathrm{kg} \text {, or SG }<1.005 \text {. First-line } \\
\text { vasopressin infusion to titrate against UO (aim } \leq 3 \mathrm{~mL} / \mathrm{kg} / \mathrm{h} \text { ) and } \mathrm{Na}<150 \mathrm{mmol} / \mathrm{L} \text {. If DI persists } \\
\text { despite vasopressin, addition of DDAVP } 1-4 \mu \mathrm{g} \text { IV boluses is indicated (titrate to effect). Enteral or IV } \\
\text { hypotonic solutions may be required to maintain euvolemia and normonatremia. } \\
\text { Tight glycemic control of } 4-10 \text { mmol/L with insulin IVI (min. } 1 \mathrm{U} / \mathrm{h} \pm \text { glucose infusion to maintain } \\
\text { blood sugar levels). } \\
\text { Maintain normothermia using humidified warm inspired gases, warming blankets, and warm IV fluids }\end{array}$ \\
\hline Immunological & Methylprednisolone 15 mg/kg (max. 1g) IV every $24 \mathrm{~h}$ \\
\hline Hematological & $\begin{array}{l}\text { Correct coagulopathy if bleeding with platelet and coagulation products to maintain international } \\
\text { normalized ratio }<1.5 \text { and platelet count of }>50,000 \mathrm{~mm}^{-3} \\
\text { Maintain } \mathrm{Hb} \geq \mathbf{7 0} \mathbf{g} / \mathbf{L} \text { and hematocrit } \geq 30 \% \\
\text { Maintain venous thromboprophylaxis measures }\end{array}$ \\
\hline Other & $\begin{array}{l}\text { Review and stop all unnecessary medications } \\
\text { Antibiotics for presumed or proven infection following full septic screen }\end{array}$ \\
\hline
\end{tabular}

Abbreviations: CV, cardiovascular; DDAVP, 1-deamino-8-D-arginine vasopressin; DI, diabetes insipidus; $\mathrm{FiO}_{2}$, fraction of inspired oxygen; Hb, hemoglobin; HT, hormone therapy; IBW, ideal body weight; IV, intravenous; IVI, intravenous infusion; LVEF, left ventricular ejection fraction; MAP, mean arterial pressure; NA, noradrenaline; $\mathrm{Na}$, sodium; $\mathrm{PaO}_{2}$, partial pressure of oxygen; PEEP, positive end-expiratory pressure; PIP, peak inspiratory pressure; SBP, systolic blood pressure; SG, specific gravity; $\mathrm{T}_{3}$, triiodothyronine; $\mathrm{T}_{4}$, tetraiodothyronine; $\mathrm{UO}$, urine output.

with studies comparing their use in DBD patients reporting either no difference in early liver graft function or impaired immediate renal graft function with colloids. ${ }^{49,50}$ However, recent studies suggest excessive crystalloids may increase the risk of delayed renal graft function, and hence advise the use of colloid boluses to minimize the volume of crystalloid. ${ }^{51}$ The Eurotransplant manual promotes fluid resuscitation with a crystalloid-to-colloid fluid ratio of 2:1. ${ }^{41}$ However, there is no evidence to support the use of colloids over crystalloids in the management of potential organ donors.

There is a balance that must be met between fluid replacement to maintain end-organ perfusion and function, especially in renal donors, versus fluid restriction to avoid organ edema, excessive lung water, and donor lung impairment. Many centers advocate the use of PAC to guide fluid management. ${ }^{42}$ The multicenter, randomized, MOnIToR trial compared usual care to protocolized fluid therapy using LiDCO Plus to target cardiac index (CI), MAP, and PPV goals. This study showed that the protocolized fluid therapy group received more fluids with no difference in the use of vasoactive drugs. However, there was no difference in the number of organs transplanted from DBD patients and recipient mortality between the two groups. ${ }^{43}$ This supports the conservative fluid management approach to maintain adequate intravascular volume, while preventing fluid overload from worsening neurogenic pulmonary edema. Several studies have shown that this conservative fluid approach increases the number of viable lungs for transplantation, while not 
affecting the viability of other donor organs, and advocates a target CVP $<6$ mm Hg. . $^{52-54}$

\section{Inotropic and Vasopressor Support}

International guidelines promote vasopressin as the first-line agent when hypotension is fluid unresponsive and promote the avoidance of catecholamines. ${ }^{35,36,40,41}$ Vasopressin has the added benefit of treating hypovolemia secondary to DI and decreasing inotropic requirements, without impairing short- or long-term renal graft function. ${ }^{35,37} \mathrm{~A}$ study showed improved long-term control of CV stability in DBD patients with the use of a pressor dose of vasopressin $(1-2 \mathrm{U} / \mathrm{h}) .^{55}$ However, a meta-analysis of two RCTs that reviewed the use of vasopressin and desmopressin in DBD patients showed no benefit on early renal graft function. ${ }^{11}$ Despite this, the high incidence of DI in DBD patients means that vasopressin still has a clinically beneficial role in controlling the associated hypernatremia, hyperosmolality, and hypovolemia. This helps minimize the need for excessive fluid infusions and prevents end-organ hypoperfusion. Also, the use of vasopressin reduces inotropic requirements and in turn decreases the associated adverse effect of exogenous catecholamines on myocardial adenosine triphosphate (ATP) depletion, which can impair posttransplant cardiac function. ${ }^{7,56}$ Also, low-dose vasopressin causes vasodilation of coronary and pulmonary arterial circulation, which improves coronary blood flow and reduces pulmonary hypertension. Thus, vasopressin is beneficial for both cardiac and lung donor organs..$^{57}$

Prior to diagnosis of brainstem death, patients may already be on vasopressor/inotropic support to achieve a desired MAP and in turn CPP. This support is usually NA in most ICUs. However, the use of NA at doses $>0.05 \mu \mathrm{g} / \mathrm{kg} / \mathrm{min}$ in DBD patients has been associated with increased right ventricular dysfunction and higher incidence of mortality in recipients. ${ }^{58}$ Also excess exogenous $\beta$-agonists can lead to $\beta$-receptor downregulation, and an animal study has shown rapid desensitization of $\beta$-receptor function post-brainstem death. ${ }^{13,59}$ Hence $\beta$-agonists should be used with caution in potential heart donors. Therefore, NA is considered a second-line agent as per international guidelines. ${ }^{35}$

Some centers advocate the use of dopamine as the first-line inotrope. Studies have shown improvement in initial renal graft function and reduced need for dialysis postrenal transplant with the use of dopamine in DBD patients, although there was no improvement in recipient suvival. ${ }^{60,61}$ However, a crossover, prospective, double-blind RCT showed that although low-dose dopamine infusions reduce renal vascular resistance in patients without acute kidney injury (AKI), dopamine actually worsens renal perfusion in the context of AKI and can induce AKI in normovolemic patients..$^{62,63}$ Also, dopamine may inhibit anterior pituitary hormone secretion, worsening brainstem death-associated endocrine dysfunction. ${ }^{63}$ Furthermore, a meta-analysis comparing NA and dopamine in patients with septic shock showed a higher incidence of arrhythmias and mortality with dopamine ${ }^{64}$ Hence, dopamine should be used with caution. If the heart is considered for donation, international guidelines advise that dopamine at the rate of $10 \mu \mathrm{g} / \mathrm{kg} / \mathrm{min}$ should not be exceeded. ${ }^{35,36}$

\section{Antiarrhythmic Support}

During and post catecholamine storm, arrhythmias are common with an incidence of $25 \%$ in DBD patients, either due to a central cause, conduction system ischemia following catecholamine storm, or electrolyte disturbance. ${ }^{19}$ Hence arrhythmias can be resistant to standard treatment. Initially, the underlying cause should be treated, if possible. The first-line management of tachyarrhythmias causing hemodynamic compromise in potential DBD patients is amiodarone. Anticholinergic drugs, such as atropine, are ineffective in the management of bradyarrhythmias that cause hemodynamic compromise. This is due to vagal nerve disruption at the level of the brainstem. Hence, adrenaline or isoprenaline is used as the first-line agent instead, and temporary pacing may be required. ${ }^{36}$

\section{Respiratory Support}

All potential DBD patients require intubation and positivepressure ventilation, which carries its own risks of barotrauma, volutrauma, and atelectotrauma. Canadian and American guidelines recommend high tidal volumes of 8 to $10 \mathrm{~mL} / \mathrm{kg}$ and positive end-expiratory pressure (PEEP) of $5 \mathrm{~cm} \mathrm{H}_{2} \mathrm{O}^{35,37}$ However, an RCT showed that adopting a lung-protective low tidal volume $(6-8 \mathrm{~mL} / \mathrm{kg})$ and high PEEP $\left(8-10 \mathrm{~cm} \mathrm{H}_{2} \mathrm{O}\right)$ strategy reduces barotrauma and increases lung donor yield..$^{65}$ Although excessive PEEP should be avoided as it can impair preload and in turn CO. Also, excessive PEEP can promote vasoconstriction through the activation of the renin-angiotensin system, leading to impaired end-organ perfusion. ${ }^{7}$

The $\mathrm{FiO}_{2}$ should be kept to a minimum to balance the need to provide adequate end-organ oxygenation and minimize the risk of potential oxygen toxicity and diffusion atelectasis. Furthermore, ventilation should be targeted to achieve normocapnia to avoid hypocapnia-associated peripheral vasoconstriction and leftward shift in the oxyhemoglobin dissociation curve, both of which may impair end-organ oxygen delivery. ${ }^{37}$

Hence, current literature promotes lung-protective ventilation strategy in potential DBD patients with (1) low tidal volume, (2) high PEEP, (3) recruitment maneuvers, (4) lowest possible $\mathrm{FiO}_{2}$ to achieve a $\mathrm{PaO}_{2} \geq 10$, and (5) relative normocapnia or hypercapnia as long as $\mathrm{pH}>7.25$ ( - Table 2). ${ }^{22,40}$

All international guidelines promote good routine respiratory care bundles. Furthermore, if the partial pressure of arterial oxygenation/fraction of inspired oxygen $\left(\mathrm{PaO}_{2} /\right.$ $\mathrm{FiO}_{2}$ ) ratio is $<300$, then it is recommended to perform chest physiotherapy, recruitment maneuvres, and diurese to normovolemia. ${ }^{35}$

Potential DBD patients considered for lung donation require a baseline chest radiograph and arterial blood gas $(A B G)$ test to assess suitability of the lungs for donation. Bronchoscopy may be considered to allow direct suctioning, bronchoalveolar lavage, and diagnosis of possible infection or suspicious lesions. ${ }^{35}$

\section{Renal Support}

Renal donor hypotension has been associated with acute tubular necrosis, renal cortical necrosis, delayed graft function, and graft rejection. Thus, the main supportive 
therapy for donor kidneys is to maintain an adequate MAP $>65 \mathrm{~mm} \mathrm{Hg}$ for renal perfusion. ${ }^{30}$ However, a retrospective review of the registry of the Eurotransplant International Foundation suggested that DBD patient treatment with catecholamines improved renal graft survival, despite no statistically significant difference in the MAP between donors receiving zero, single, and combined catecholamines. ${ }^{66}$ This adds weight to the theory of the immunomodulatory effects of catecholamines improving renal graft survival.

Potential DBD patients considered for renal donation should have urinalysis and baseline creatine, urea, and creatine clearance rate measured. ${ }^{35}$ Also, one should avoid nephrotoxic drugs and minimize exposure to intravenous contrast in these patients.

\section{Hepatic Support}

Adequate nutrition to maintain liver glycogen stores has been shown to reduce liver graft loss; thus, nutritional support via continuous enteral feeding is required. ${ }^{13}$

DBD patient hypernatremia has been associated with increased liver recipient death and retransplantation. This is possibly due to osmotic shifts and cell lysis when a liver exposed to a hyperosmotic environment is transplanted into a normosmolar recipient. ${ }^{67}$ However, a subsequent retrospective study found no correlation between DBD patient serum sodium $(\mathrm{Na})$ levels and early liver graft function or 1-year graft survival..$^{68}$ Hence, it has been suggested that hypernatremia itself may not be the underlying cause of impaired liver graft outcome, but instead a marker of poor DBD patient management. ${ }^{22}$ Nevertheless, international guidelines recommend maintaining a serum $\mathrm{Na}<150 \mathrm{mmol} / \mathrm{L}$ with hypotonic intravenous solutions or nasogastric (NG) water. ${ }^{35,36}$

Literature recommends maintaining CVP $<10 \mathrm{~mm} \mathrm{Hg}$ and PEEP $<10 \mathrm{~cm} \mathrm{H}_{2} \mathrm{O}$ to help reduce hepatic congestion. ${ }^{47}$ However, there is no study to suggest that these measures have any beneficial effect on liver transplant recipient outcomes.

Potential DBD patients considered for liver donation need liver function tests, coagulation screen, and hepatitis screen. Canadian guidelines recommend a liver biopsy prior to retrieval if the donor is obese or hepatitis $\mathrm{C}$ antibody positive to clarify transplantability. ${ }^{35}$

\section{Endocrine and Immunological Support Combined or Triple Hormonal Therapy}

A retrospective study showed that $25 \%$ of potential DBD patients die prior to donating organs due to failure of physiological support despite maximal conventional therapy ${ }^{69}$

Therefore, the concept of combined or triple hormonal therapy (HT) was introduced to help maintain hemodynamic stability. The traditional HT strategy, using hourly doses of triiodothyronine $\left(\mathrm{T}_{3}\right) 2 \mu \mathrm{g}$, cortisol $100 \mathrm{mg}$, and insulin 20 units, has been shown to improve CV status, reduce inotropic requirements, and increase the number of organs transplanted per donor. ${ }^{29}$ The current combined HT consists of methylprednisolone, vasopressin, and either $\mathrm{T}_{3}$ or tetraiodothyronine $\left(\mathrm{T}_{4}\right)$. A retrospective study of 10,292 DBD patients showed an increase in the number of organs transplanted per donor in those treated with combined HT compared with
non-HT-treated donors. ${ }^{70}$ Similarly, a retrospective analysis of 18,726 DBD patients from the United Network for Organ Sharing database showed the use of combined HT was associated with more organ yield and increased renal graft and heart transplant recipient survival, but no change in liver transplant recipient survival. ${ }^{71}$ However, currently there is no RCT to support routine use of combined HT. Hence, international guidelines recommend consideration of combined HT only if LVEF $\leq 40 \%$ or hemodynamic instability remains despite conventional therapy. ${ }^{35,36}$

\section{Thyroid Support}

A prospective, non-RCT showed decreased vasopressor requirements with $T_{3}$ infusions in DBD patients who remained hemodynamically unstable despite fluid, inotropic, and vasopressor resuscitation..$^{31}$ In contrast, two separate meta-analyses of four prospective double-blind RCTs comparing intravenous $\mathrm{T}_{3}$ with placebo in DBD patients showed no difference in Cl. ${ }^{11,72}$ However, one RCT not included in these meta-analyses has shown that using $T_{3}$ reduced inotropic requirements in terms of dose and duration. ${ }^{73}$ Furthermore, a subsequent retrospective study showed that $\mathrm{T}_{3}$ or $\mathrm{T}_{4}$ therapy resulted in more transplantable organs per donor. ${ }^{74}$ Thus, on the basis of current evidence, reduced $\mathrm{T}_{3}$ does not seem to be a major contributor to CV instability in DBD patients, and there is a low level of evidence to support its routine use. Nevertheless, $\mathrm{T}_{3}$ may still be a useful adjunct in the patients who remain CV unstable despite conventional therapy.

\section{Immunological Support}

The systemic inflammatory state that occurs post-brainstem death may affect $\mathrm{CV}$ stability, worsen neurogenic pulmonary edema, and increase donor organ rejection. ${ }^{34}$ In theory, the use of corticosteroids should suppress this inflammatory state and improve $\mathrm{CV}$ responsiveness to catecholamines and in turn have a catecholamine-sparing effect.

A retrospective study has suggested that the use of high-dose methylprednisolone in DBD patients is associated with improved oxygenation and resulted in more lungs transplanted. ${ }^{75}$ However, an RCT showed DBD patient treatment with methylprednisolone decreased pulmonary water accumulation but did not increase donor lung yield. ${ }^{9}$

A prospective RCT showed reduced levels of cytokines and adhesion molecules in methylprednisolone-treated DBD patients compared with controls, resulting in reduced incidence of acute liver graft rejection. ${ }^{76}$ However, a prospective, double-blind RCT comparing DBD patients pretreatment with methylprednisolone and no pretreatment prior to organ donation showed no difference in early renal graft function. ${ }^{77}$

A multicenter prospective study comparing hydrocortisone DBD patient therapy with controls concluded no difference in functional recovery of transplant grafts. However, steroid therapy was associated with improved CV stability, and hence the study supported steroid use in hemodynamically unstable potential DBD patients. ${ }^{78}$

In summary, although the current evidence is equivocal, international guidelines advocate the use of methylprednisolone $15 \mathrm{mg} / \mathrm{kg}$ to all potential DBD patients. 35,36 


\section{Management of Diabetes Insipid}

Early recognition and appropriate management of DI are key to maintain hemodynamic stability. One should consider DI if urine output (UO) $>4 \mathrm{~mL} / \mathrm{kg} / \mathrm{h}$ with serum $\mathrm{Na} \geq 145 \mathrm{mmol} / \mathrm{L}$, and/or serum osmolarity $\geq 300 \mathrm{mOsmol} / \mathrm{kg}$, and/or urine osmolarity $\leq 200 \mathrm{mOsmol} / \mathrm{kg}$, or specific gravity $<1.005 .{ }^{35}$ International guidelines promote management of DI with a continuous vasopressin infusion instead of intermittent desmopressin (DDAVP, 1-deamino-8-D-arginine vasopressin) boluses. This is because vasopressin has 1,500 times greater vasoconstrictor action and a shorter elimination half-life than DDAVP, even though vasopressin has 10 times less antidiuretic action than DDAVP. Hence, vasopressin has the added benefits of vasopressor activity and ease of titration against $\mathrm{UO}$ (aim $\leq$ $3 \mathrm{~mL} / \mathrm{kg} / \mathrm{h}$ ) and $\mathrm{Na}$ target ( $<150 \mathrm{mmol} / \mathrm{L}$ ). However, if DI persists despite the administration of vasopressin, the addition of DDAVP 1 to $4 \mu \mathrm{g}$ intravenous boluses is indicated. ${ }^{35,79}$ Furthermore, enteral or intravenous hypotonic solutions may be required to maintain euvolemia and normonatremia. ${ }^{47}$

\section{Glycemic Control}

DBD patient hyperglycemia has been implicated as a risk factor for (1) pancreatic transplant failure due to direct pancreatic $\beta$-cell damage, (2) renal graft impairment, and (3) hypovolemia secondary to osmotic diuresis. Hence, many guidelines advocate tight glycemic control of 4 to $10 \mathrm{mmol} / \mathrm{L}$ with an insulin infusion. $35,36,40,80$

\section{Thermoregulation}

As described previously, hypothermia and associated adverse effects are common in DBD patients. However, an RCT found that maintenance of therapeutic hypothermia of 34 to $35^{\circ} \mathrm{C}$ in DBD patients was associated with reduced rate of delayed graft function. ${ }^{81}$ Despite this, current guidelines promote maintenance of normothermia using humidified warm inspired gases, warming blankets, and warm intravenous fluids. ${ }^{7}$ Thus, all potential donors should have invasive temperature monitoring.

\section{Hematological Support}

Plasminogen activator and thromboplastin released from ischemic or necrotic brain tissue in brainstem-dead patients may stimulate DIC, leading to fibrin deposits within organs. These fibrin deposits may impair posttransplant organ function. ${ }^{33}$ Hence early recognition and support of coagulopathy with clotting factors and platelet replacement are required to achieve international targets of an international normalized ratio $<1.5$ and platelet count of $>50,000 \mathrm{~mm}^{-3} .{ }^{13}$

Blood transfusion is indicated if hemoglobin concentration falls $<70 \mathrm{~g} / \mathrm{L}$ as per NICE 2015 guidelines. ${ }^{82}$ International DBD patient management guidelines also recommend blood transfusion to maintain hematocrit $\geq 30 \%$ to optimize oxygen delivery. 35,36

\section{Organizational Treatment Approach}

Care of the organ donor requires a multidisciplinary team (MDT) approach involving communication and collaborative work between ICU, retrieval, and Specialist Nurses-Organ Donation (SN-OD) teams to achieve the best outcome for the donor, donor's family, and the recipient. A retrospective analysis has shown that the implementation of an intensive care physician-led organ donor support team improved the number of transplantable organs from 66 (31\%) out of 210 potential DBD organs to 113 (43\%) out of 258 potential DBD organs. ${ }^{83}$ Therefore, Eurotransplant guidelines advise that the ICU physician should act as the responsible clinician for donor management and the UK National Organ Donation Committee promote all trusts to appoint clinical leads for organ donation..$^{19,41}$

Organs used to be recovered as soon as possible due to concerns over loss of unstable potential DBD patients. Now with improved potential DBD patient care, the timing of organ retrieval depends on which organs have been accepted for transplantation. One retrospective study showed that the longer the donor management time (brainstem death to retrieval time), the poorer the heart transplant recipient outcome. ${ }^{84}$ However, another retrospective review showed that the quality and quantity of all types of transplantable solid organs do not decline with prolonged donor management time. ${ }^{85}$ In fact, subsequent retrospective studies have shown reduced rate of delayed renal graft function and improved lung function associated with longer donor management time and advocated a relax and repair strategy. ${ }^{86,87}$ Furthermore, early active potential DBD patient management has been shown in an RCT to be associated with increased lung yield. ${ }^{9}$ Thus, these studies highlight the importance of early identification of brainstem death and early institution of active donor management, to maximize the time available to optimize organ function prior to planned organ retrieval.

The importance of an aggressive donor management protocol was highlighted by the Papworth hospital transplant program study, which showed that utilization of potential DBD patient management protocol improved the function of $92 \%$ of organs that were initially considered unsuitable for transplantation. ${ }^{42}$ Similarly, a prospective study involving 88 ICUs in the United States has shown that the implementation of a structured potential DBD patient management algorithm improved the number of organs retrieved and transplanted without impairing the quality of the organs..$^{10}$ Furthermore, a retrospective study showed that the implementation of an aggressive donor management protocol decreased donors lost as a result of hemodynamic instability (by 87\%), increasing the number of actual donors (by $82 \%$ ) and organs retrieved (by $71 \%){ }^{88}$ Another retrospective study showed that utilization of aggressive potential DBD patient management protocol could convert initially unsuitable donor lungs to transplantable ones, with no difference in 1-year graft survival. ${ }^{89}$ Hence, the UK National Organ Donation Committee have endorsed a donor optimization care bundle and promotes its adoption by local donation committees' ICUs. ${ }^{19}$

\section{Conclusion}

The incidence and the severity of the pathophysiological changes post-brainstem death depend on the etiology, speed 
of onset, and duration of brainstem death. A good understanding of these pathophysiological changes allows effective active donor management strategies to be implemented to maintain the functional integrity of the organs.

Although there is a low level of evidence to support specific management strategies to optimize the care of potential DBD patients, there is reasonable consensus between different international guidelines on protocolized ICU management of potential DBD patients and donor resuscitation targets. Hence, we recommend that all ICUs develop local potential DBD patient protocolized management guidelines to optimize transplanted organ outcome.

Key management concepts include (1) early recognition of brainstem death and referral to organ donation services, (2) ICU-led MDT approach to donor management, (3) shift in ICU teams thinking from management of raised ICP to maintaining organ perfusion and function, (4) early active donor management to normalize donor physiology, and (5) prevention, recognition, and treatment of complications of brainstem death.

\section{Conflict of Interest}

None declared.

\section{References}

1 NHS Blood and Transplant. Organ Donation and Transplantation Activity Report; 2017/18[Online]. Available at: https://nhsbtdbe.blob.core.windows.net/umbraco-assets-corp/12300/transplant-activity-report-2017-2018.pdf. Accessed January 1, 2018

2 Academy of Medical Royal Colleges. "A Code of Practice for the Diagnosis and Confirmation of Death." AoMRC; 2008 [Online]. Available at:http://www.aomrc.org.uk. Accessed January 1, 2018

3 Report from the Organ Donation Taskforce. "Organs for transplant”; 2008 [Online]. Available at:https://webarchive.nationalarchives.gov.uk/20130105051141/http://www.dh.gov.uk/ en/Publicationsandstatistics/Publications/PublicationsPolicyAndGuidance/DH_082122Accessed January 1, 2018

4 National Institute for Clinical Excellence (NICE). Organ donation for transplantation: improving donor identification and consent rates for deceased organ donation. Issue date: December 2011. NICE guideline CG135. Last updated December 2016.[Online].Availableat:https://www.nice.org.uk/guidance/ cg135/evidence/full-guideline-184994893. Accessed January 1,2018

5 Reyes KG, Mason DP, Thuita L, et al. Guidelines for donor lung selection: time for revision? Ann Thorac Surg 2010;89(6):1756-1764, discussion 1764-1765

6 Bugge JF. Brain death and its implications for management of the potential organ donor. Acta Anaesthesiol Scand 2009;53(10):1239-1250

7 Smith M. Physiologic changes during brain stem deathlessons for management of the organ donor. J Heart Lung Transplant 2004;23(9, Suppl):S217-S222

8 Robert R, Guilhot J, Pinsard M, et al. A pair analysis of the delayed graft function in kidney recipient: the critical role of the donor. J Crit Care 2010;25(4):582-590

9 Venkateswaran RV, Patchell VB, Wilson IC, et al. Early donor management increases the retrieval rate of lungs for transplantation. Ann Thorac Surg 2008;85(1):278-286, discussion 286
10 Rosendale JD, Chabalewski FL, McBride MA, et al. Increased transplanted organs from the use of a standardized donor management protocol. Am J Transplant 2002;2(8):761-768

11 Rech TH, Moraes RB, Crispim D, Czepielewski MA, Leitão CB. Management of the brain-dead organ donor: a systematic review and meta-analysis. Transplantation 2013;95(7):966-974

12 Prout J, Jones T, Martin D, eds. Advanced training in Anaesthesia the Essential Curriculum. Oxford, UK: Oxford University Press; 2014:402-403

13 Dictus C, Vienenkoetter B, Esmaeilzadeh M, Unterberg A, Ahmadi R. Critical care management of potential organ donors: our current standard. Clin Transplant 2009;23 (Suppl 21):2-9

14 Agrawal A, Timothy J, Cincu R, Agarwal T, Waghmare LB. Bradycardia in neurosurgery. Clin Neurol Neurosurg 2008; 110(4):321-327

15 Fraser JF, Nataatmadja M, Passmore M, et al. Brain stem death induced pulmonary hypertension-more pronounced and prolonged than left ventricular changes in an ovine model. J Heart Lung Transplant 2009;18(1):74

16 Halejcio-Delophont P, Siaghy EM, Devaux Y, et al. Increase in myocardial interstitial adenosine and net lactate production in brain-dead pigs: an in vivo microdialysis study. Transplantation 1998;66(10):1278-1284

17 Shivalkar B, Van Loon J, Wieland W, et al. Variable effects of explosive or gradual increase of intracranial pressure on myocardial structure and function. Circulation 1993;87(1): 230-239

18 Novitzky D, Rhodin J, Cooper DK, Ye Y, Min KW, DeBault L. Ultrastructure changes associated with brain death in the human donor heart. Transpl Int 1997;10(1):24-32

19 ODT clinical, . Donor optimisation: Guidance around selecting potential DBD donors [Online]. Available at: https://www. odt.nhs.uk/deceased-donation/best-practice-guidance/ donor-optimisation/. Accessed January 1, 2018

20 Chudoba P, Krajewski W, Wojciechowska J, Kamińska D. Brain death-associated pathological events and therapeutic options. Adv Clin Exp Med 2017;26(9):1457-1464

21 Avlonitis VS, Wigfield CH, Kirby JA, Dark JH. The hemodynamic mechanisms of lung injury and systemic inflammatory response following brain death in the transplant donor. Am J Transplant 2005;5(4 Pt 1):684-693

22 McKeown DW, Bonser RS, Kellum JA. Management of the heart beating brain-dead organ donor. Br J Anaesth 2012;108 (Suppl 1):i96-i107

23 Novitzky D, Cooper DK, Rosendale JD, Kauffman HM. Hormonal therapy of the brain-dead organ donor: experimental and clinical studies. Transplantation 2006;82(11):1396-1401

24 Gramm HJ, Meinhold H, Bickel U, et al. Acute endocrine failure after brain death? Transplantation 1992;54(5):851-857

25 Chen EP, Bittner HB, Kendall SW, Van Trigt P. Hormonal and hemodynamic changes in a validated animal model of brain death. Crit Care Med 1996;24(8):1352-1359

26 Dimopoulou I, Tsagarakis S, Anthi A, et al. High prevalence of decreased cortisol reserve in brain-dead potential organ donors. Crit Care Med 2003;31(4):1113-1117

27 Powner DJ, Hendrich A, Lagler RG, Ng RH, Madden RL. Hormonal changes in brain dead patients. Crit Care Med 1990;18(7):702-708

28 Masson F, Thicoïpe M, Latapie MJ, Maurette P. Thyroid function in brain-dead donors. Transpl Int 1990;3(4):226-233

29 Novitzky D, Cooper DK, Reichart B. Hemodynamic and metabolic responses to hormonal therapy in brain-dead potential organ donors. Transplantation 1987;43(6):852-854

30 Domi R, Sula H, Ohri I, Laho H. Pathophysiologic changes after brain death and organ preservation: the intensivist's and anesthesiologist's role. J Anesth Clin Res 2013;4(3):1-4 
31 Salim A, Vassiliu P, Velmahos GC, et al. The role of thyroid hormone administration in potential organ donors. Arch Surg 2001;136(12):1377-1380

32 Masson F, Thicoipe M, Gin H, et al. The endocrine pancreas in brain-dead donors. A prospective study in 25 patients. Transplantation 1993;56(2):363-367

33 Hefty TR, Cotterell LW, Fraser SC, Goodnight SH, Hatch TR. Disseminated intravascular coagulation in cadaveric organ donors. Incidence and effect on renal transplantation. Transplantation 1993;55(2):442-443

34 Pratschke J, Wilhelm MJ, Kusaka M, et al. Accelerated rejection of renal allografts from brain-dead donors. Ann Surg 2000;232(2):263-271

35 Shemie SD, Ross H, Pagliarello J, et al; Pediatric Recommendations Group. Organ donor management in Canada: recommendations of the forum on medical management to optimize donor organ potential. CMAJ 2006;174(6):S13-S32

36 Zaroff JG, Rosengard BR, Armstrong WF, et al. Consensus conference report: maximizing use of organs recovered from the cadaver donor: cardiac recommendations March 28-29 2001, Crystal City, Va. Circulation 2002;106(7):836-41

37 Wood KE, Becker BN, McCartney JG, D'Alessandro AM, Coursin DB. Care of the potential organ donor. N Engl J Med 2004;351(26):2730-2739

38 United Network for Organ Sharing (UNOS). Critical Pathway for Organ Donor. UNOS;2002[Online]. Available at: https:// www.unos.org/wp-content/uploads/unos/Critical_Pathway. pdf. Accessed January 1, 2018

39 Faculty of Intensive Care Medicine (FICM). Form for the Diagnosis of Death using Neurological Criteria [full guidance version]. FICM;2014[Online]. Available at:https://www.ficm. ac.uk/sites/default/files/Form\%20for\%20the\%20Diagnosis\%20 of\%20Death\%20using\%20Neurological\%20Criteria\%20-\%20 Full\%20Version\%20\%282014\%29.pdf. Accessed January 1, 2018

40 Mandersloot G. Donation after Brainstem Death (DBD) Donor Optimisation Extended Care Bundle version 2009-2012. National Organ Donation Committee;2012[Online]. Available at:https://www.odt.nhs.uk/deceased-donation/best-practice-guidance/donor-optimisation/. Accessed January 1, 2018

41 Chapter 9: The donor. In: Eurotransplant Manual-version 4.3; June 2,2015. [Online]. Available at:https://eurotransplant.org/ cms/mediaobject.php?file=H9+The+Donor_August+20161. pdf. Accessed January 1, 2018

42 Wheeldon DR, Potter CD, Oduro A, Wallwork J, Large SR. Transforming the "unacceptable" donor: outcomes from the adoption of a standardized donor management technique. J Heart Lung Transplant 1995;14(4):734-742

43 Al-Khafaji A, Elder M, Lebovitz DJ, et al. Protocolized fluid therapy in brain-dead donors: the multicenter randomized MOnIToR trial. Intensive Care Med 2015;41(3):418-426

44 Venkateswaran RV, Townend JN, Wilson IC, Mascaro JG, Bonser RS, Steeds RP. Echocardiography in the potential heart donor. Transplantation 2010;89(7):894-901

45 Vijay P, Scavo VA, Morelock RJ, Sharp TG, Brown JW. Donor cardiac troponin $\mathrm{T}$ : a marker to predict heart transplant rejection. Ann Thorac Surg 1998;66(6):1934-1939

46 Audibert G, Charpentier C, Seguin-Devaux C, et al. Improvement of donor myocardial function after treatment of autonomic storm during brain death. Transplantation 2006;82(8): 1031-1036

47 Gordon JK, McKinlay J. Physiological changes after brain stem death and management of the heart-beating donor. Contin Educ Anaesth Crit Care Pain 2012;12(5):225-229

48 Murugan R, Venkataraman R, Wahed AS, et al; HIDonOR Study Investigators. Preload responsiveness is associated with increased interleukin-6 and lower organ yield from braindead donors. Crit Care Med 2009;37(8):2387-2393
49 Randell T, Orko R, Höckerstedt K. Peroperative fluid management of the brain-dead multiorgan donor. Acta Anaesthesiol Scand 1990;34(7):592-595

50 Cittanova ML, Leblanc I, Legendre C, Mouquet C, Riou B, Coriat P. Effect of hydroxyethylstarch in brain-dead kidney donors on renal function in kidney-transplant recipients. Lancet 1996;348(9042):1620-1622

51 Limnell N, Schramko AA. Is brain-dead donor fluid therapy with colloids associated with better kidney grafts? Exp Clin Transplant 2018;16(1):55-60

52 Pennefather SH, Bullock RE, Dark JH. The effect of fluid therapy on alveolar arterial oxygen gradient in brain-dead organ donors. Transplantation 1993;56(6):1418-1422

53 Angel LF, Levine DJ, Restrepo MI, et al. Impact of a lung transplantation donor-management protocol on lung donation and recipient outcomes. Am J Respir Crit Care Med 2006;174(6): 710-716

54 Miñambres E, Rodrigo E, Ballesteros MA, et al. Impact of restrictive fluid balance focused to increase lung procurement on renal function after kidney transplantation. Nephrol Dial Transplant 2010;25(7):2352-2356

55 Iwai A, Sakano T, Uenishi M, Sugimoto H, Yoshioka T, Sugimoto T. Effects of vasopressin and catecholamines on the maintenance of circulatory stability in brain-dead patients. Transplantation 1989;48(4):613-617

56 Chen JM, Cullinane S, Spanier TB, et al. Vasopressin deficiency and pressor hypersensitivity in hemodynamically unstable organ donors. Circulation 1999;100(19, Suppl):II244-II246

57 Holmes CL, Patel BM, Russell JA, Walley KR. Physiology of vasopressin relevant to management of septic shock. Chest 2001;120(3):989-1002

58 Stoica SC, Satchithananda DK, White PA, Parameshwar J, Redington AN, Large SR. Noradrenaline use in the human donor and relationship with load-independent right ventricular contractility. Transplantation 2004;78(8):1193-1197

59 D'Amico TA, Meyers CH, Koutlas TC, et al. Desensitization of myocardial beta-adrenergic receptors and deterioration of left ventricular function after brain death. J Thorac Cardiovasc Surg 1995;110(3):746-751

60 Schnuelle P, Yard BA, Braun C, et al. Impact of donor dopamine on immediate graft function after kidney transplantation. Am J Transplant 2004;4(3):419-426

61 Schnuelle P, Gottmann U, Hoeger S, et al. Effects of donor pretreatment with dopamine on graft function after kidney transplantation: a randomized controlled trial. JAMA 2009;302(10): 1067-1075

62 Lauschke A, Teichgräber UK, Frei U, Eckardt KU. 'Low-dose' dopamine worsens renal perfusion in patients with acute renal failure. Kidney Int 2006;69(9):1669-1674

63 Debaveye YA, Van den Berghe GH. Is there still a place for dopamine in the modern intensive care unit? Anesth Analg 2004;98(2):461-468

64 De Backer D, Aldecoa C, Njimi H, Vincent JL. Dopamine versus norepinephrine in the treatment of septic shock: a meta-analysis. Crit Care Med 2012;40(3):725-730

65 Mascia L, Pasero D, Slutsky AS, et al. Effect of a lung protective strategy for organ donors on eligibility and availability of lungs for transplantation: a randomized controlled trial. JAMA 2010;304(23):2620-2627

66 Schnuelle P, Berger S, de Boer J, Persijn G, van der Woude FJ. Effects of catecholamine application to brain-dead donors on graft survival in solid organ transplantation. Transplantation 2001;72(3):455-463

67 Totsuka E, Dodson F, Urakami A, et al. Influence of high donor serum sodium levels on early postoperative graft function in human liver transplantation: effect of correction of donor hypernatremia. Liver Transpl Surg 1999;5(5):421-428 
68 Mangus RS, Fridell JA, Vianna RM, et al. Severe hypernatremia in deceased liver donors does not impact early transplant outcome. Transplantation 2010;90(4):438-443

69 Mackersie RC, Bronsther OL, Shackford SR. Organ procurement in patients with fatal head injuries. The fate of the potential donor. Ann Surg 1991;213(2):143-150

70 Rosendale JD, Kauffman HM, McBride MA, et al. Aggressive pharmacologic donor management results in more transplanted organs. Transplantation 2003;75(4):482-487

71 Rosendale JD, Kauffman HM, McBride MA, Skjei TC. Hormonal resuscitation associated with more transplanted organs with no sacrifice in survival. Transplantation 2004;78(2):17

72 Macdonald PS, Aneman A, Bhonagiri D, et al. A systematic review and meta-analysis of clinical trials of thyroid hormone administration to brain dead potential organ donors. Crit Care Med 2012;40(5):1635-1644

73 Jeevanandam V. Triiodothyronine: spectrum of use in heart transplantation. Thyroid 1997;7(1):139-145

74 Novitzky D, Mi Z, Sun Q, Collins JF, Cooper DK. Thyroid hormone therapy in the management of 63,593 brain-dead organ donors: a retrospective analysis. Transplantation 2014;98(10): 1119-1127

75 Follette DM, Rudich SM, Babcock WD. Improved oxygenation and increased lung donor recovery with high-dose steroid administration after brain death. J Heart Lung Transplant 1998;17(4):423-429

76 Kotsch K, Ulrich F, Reutzel-Selke A, et al. Methylprednisolone therapy in deceased donors reduces inflammation in the donor liver and improves outcome after liver transplantation: a prospective randomized controlled trial. Ann Surg 2008;248 (6):1042-1050

77 Chatterjee SN, Terasaki PI, Fine S, Schulman B, Smith R, Fine RN. Pretreatment of cadaver donors with methylprednisolone in human renal allografts. Surg Gynecol Obstet 1977;145(5):729-732

78 Pinsard M, Ragot S, Mertes PM, et al. Interest of low-dose hydrocortisone therapy during brain-dead organ donor resuscitation: the CORTICOME study. Crit Care 2014;18(4):R158

79 Sharman A, Low J. Vasopressin and its role in critical care. Contin Educ Anaesth Crit Care Pain 2008;8(4):134-137
80 Blasi-Ibanez A, Hirose R, Feiner J, et al. Predictors associated with terminal renal function in deceased organ donors in the intensive care unit. Anesthesiology 2009;110(2):333-341

81 Niemann CU, Feiner J, Swain S, et al. Therapeutic hypothermia in deceased organ donors and kidney-graft function. $\mathrm{N}$ Engl J Med 2015;373(5):405-414

82 National Institute for Clinical Excellence (NICE). Blood transfusion. NICE guideline; November 2015 [Online]. Available at: nice.org.uk/guidance/ng24. Accessed January 1, 2018

83 Singbartl K, Murugan R, Kaynar AM, et al. Intensivist-led management of brain-dead donors is associated with an increase in organ recovery for transplantation. Am J Transplant 2011;11(7):1517-1521

84 Cantin B, Kwok BW, Chan MC, et al. The impact of brain death on survival after heart transplantation: time is of the essence. Transplantation 2003;76(9):1275-1279

85 Inaba $\mathrm{K}$, Branco BC, Lam L, et al. Organ donation and time to procurement: late is not too late. J Trauma 2010;68(6):1362-1366

86 Nijboer WN, Moers C, Leuvenink HGD, Ploeg RJ. How important is the duration of the brain death period for the outcome in kidney transplantation? Transpl Int 2011;24(1): $14-20$

87 Wauters S, Verleden GM, Belmans A, et al. Donor cause of brain death and related time intervals: does it affect outcome after lung transplantation? Eur J Cardiothorac Surg 2011;39(4):e68-e76

88 Salim A, Velmahos GC, Brown C, Belzberg H, Demetriades D. Aggressive organ donor management significantly increases the number of organs available for transplantation. J Trauma 2005;58(5):991-994

89 Straznicka M, Follette DM, Eisner MD, Roberts PF, Menza RL, Babcock WD. Aggressive management of lung donors classified as unacceptable: excellent recipient survival one year after transplantation. J Thorac Cardiovasc Surg 2002;124(2):250-258 